\title{
ALGUNAS IDEAS SOBRE LA PARTICIPACIÓN CIUDADANA EN EL PROYECTO DE LEY MARCO DE CAMBIO CLIMÁTICO
}

SOME IDEAS ON CITIZEN PARTICIPATION IN THE DRAFT FRAMEWORK LAW ON CLIMATE CHANGE

\begin{tabular}{|c|c|}
\hline \multicolumn{2}{|c|}{ ARTÍCULO INÉDITO DE INVESTIGACIÓN } \\
\hline CÓMO CITAR ESTE ARTÍCULO (CHICAGO) & $\begin{array}{l}\text { Riesco Eyzaguirre, Felipe. «Algunas ideas } \\
\text { sobre la participación ciudadana en el pro- } \\
\text { yecto de ley marco de cambio climático». } \\
\text { Revista de Derecho Aplicado LLM UC } 7 \text { (202I). } \\
\text { https://doi.org/10.776//rda.o.7.3216I }\end{array}$ \\
\hline \multirow[t]{2}{*}{ REVISTA DE DERECHO APLICADO LLM UC } & $\begin{array}{l}\text { Número } 7 \\
\text { Julio } 2021 \\
\text { ISSN: } 245^{2-4344}\end{array}$ \\
\hline & $\begin{array}{l}\text { Recepción: } \mathrm{I}_{4} \text { de abril, 202I } \\
\text { Aceptación: } 5 \text { de mayo, 202I }\end{array}$ \\
\hline
\end{tabular}




\section{Resumen}

El presente artículo analiza la participación ambiental ciudadana a nivel constitucional y su desarrollo en la legislación ambiental chilena, a fin de determinar si el proyecto de ley marco de cambio climático establece mecanismos participativos con el nivel de regulación, detalle y densidad normativa que resultan exigibles en nuestro régimen constitucional.

Palabras clave: Ley marco de cambio climático, participación ciudadana, derecho a vivir en un medio ambiente libre de contaminación, legislación ambiental chilena.

\section{Abstract}

This article is dedicated to analyzing citizen environmental participation at the constitutional level and its development in Chilean environmental legislation, determining whether the draft climate change framework law establishes mechanisms for citizen participation, and whether it sufficiently regulates these mechanisms in the law, and if this regulation has sufficient normative density, considering our constitutional and legal regime on environmental matters.

Keywords: Framework Law on Climate Change, citizen participation, right to live in a pollution-free environment, Chilean environmental legislation. 


\section{Felipe Riesco Eyzaguirre}

Barros Silva Varela \& Vigil

Santiago, Chile

friesco@bsvv.cl
Barros Silva Varela \& Vigil

Santiago, Chile

friesco@bsvv.cl
Licenciado en Ciencias Jurídicas y Sociales, Pontificia Universidad Católica de Chile. Abogado. Candidato a magíster en Derecho Constitucional con mención en Derecho Procesal Constitucional de la Universidad de Talca. Diplomado en Derecho Administrativo Sancionatorio Universidad de Valladolid. Coautor, en conjunto con Leslie Cannoni Mandujano y Cristóbal Osorio Vargas, de «El carácter integrador de la legislación y de los instrumentos de gestión ambiental, y la competencia exclusiva y excluyente de la Superintendencia del Medio Ambiente para la fiscalización, seguimiento y sanción de los instrumentos de gestión ambiental establecidos en el artículo 2 de la Ley Orgánica de la Superintendencia del Medio Ambiente», en Revista de Derecho Ambiental 5 (2015). Abogado socio en el área de derecho público, regulatorio y medio ambiente del estudio jurídico Barros Silva Varela \& Vigil. Miembro de la Asociación Chilena de Derecho Ambiental (2020).

Degree in Legal and Social Sciences, Law School, Pontificia Universidad Católica de Chile. LL.M. candidate, Constitutional Law, with special mention in Constitutional Procedural Law, Law School, University of Talca. Graduate Diploma in Punitive Administrative Law, Law School, University of Valladolid. Co-author, with Leslie Cannoni Mandujano and Cristóbal Osorio Vargas, of «The integrative nature of legislation and environmental management instruments, and the exclusive competence of the Superintendency of the Environment for the inspection, monitoring, and penalization of the environmental management instruments established in article 2 of the Organic Law of the Superintendency of the Environment", published in Environmental Law Magazine Vol. 5 (2015). Partner at Barros Silva Varela \& Vigil and head of the firm's Public, Regulatory, and Environmental Law practice. Member of the Chilean Association of Environmental Law (2020). 


\section{INTRODUCCIÓN}

El derecho a la participación pública ha sido reconocido en los estándares internacionales de derechos humanos, y ampliamente desarrollado en el marco del sistema de derechos humanos de las Naciones Unidas como derecho civil y político.

Así, por ejemplo, la Declaración Universal de Derechos Humanos de 1948, en su artículo 21.1, establece que «toda persona tiene derecho a participar en el Gobierno de su país, directamente o por medio de representantes libremente escogidos».

También el Pacto Internacional de Derechos Civiles y Políticos de 1966 dispone en su artículo 25 que «todos los ciudadanos gozarán, sin ninguna de las distinciones mencionadas en el artículo 2, y sin restricciones indebidas, de los siguientes derechos y oportunidades: a) Participar en la dirección de los asuntos públicos, directamente o por medio de representantes libremente elegidos».

La Constitución Política de la República de Chile, por su parte, consagra en el capítulo primero, sobre «Bases de la institucionalidad», el deber del Estado de «asegurar el derecho de las personas a participar con igualdad de oportunidades en la vida nacional» (artículo 1, inciso final); y aunque no lo incluye luego dentro del capítulo tercero de los derechos y deberes constitucionales expresamente, se ha estimado que

el derecho a la participación se cristaliza a través del derecho de las personas a participar con igualdad de oportunidades en la vida nacional (artículo 1 inciso cuarto), el derecho a voto (artículo 13), la igualdad ante la ley (artículo 19, numeral segundo), la libertad de opinión (artículo 19, numeral decimosegundo) y la libertad de reunión (artículo 19, numeral decimotercero), el derecho de petición (artículo 19, numeral decimocuarto), el derecho de asociación (artículo 19, numeral decimoquinto) y el acceso a cargos públicos (artículo 19, numeral decimoséptimo). ${ }^{1}$

En materia ambiental, nuestra Constitución reconoce y asegura a todas las personas, en su artículo 19, numeral octavo, «el derecho a vivir en un medio ambiente libre de contaminación», para disponer luego que «es deber del Estado velar para que este derecho no sea afectado y tutelar la preservación de la naturaleza» y, de forma específica. Que «la ley podrá establecer restricciones específicas al ejercicio de determinados derechos o libertades para proteger el medio ambiente».

1 «Participación en condiciones de igualdad en la vida pública y política», Instituto Nacional de Derechos Humanos, I2 de febrero de 20I8, https://bibliotecadigital.indh.cl/bitstream/handle/r23356789/ri63/Informe\%20ACNUDH\%2oderecho\%20a\%2ola\%2oparticipaci\%C $3 \%$ B 3 n.pdf. 
Como puede apreciarse, el constituyente no delimitó el derecho a vivir en un medio ambiente libre de contaminación. De hecho, la Constitución no determina qué debe entenderse por «medio ambiente», ni menos por «medio ambiente libre de contaminación», sino que deja al legislador, en virtud de la cláusula general del artículo 19, numeral 26. ${ }^{\circ}$, la regulación o complementación de este derecho, así como su posible limitación, según lo dispuesto en el inciso final del artículo 19, numeral octavo.

La Ley 19.300, sobre Bases Generales del Medio Ambiente, constituye - en línea con los numerales octavo y $26 .^{\circ}$ del artículo 19 de la Constitución- la regulación de este derecho y del deber del Estado de tutelar la preservación de la naturaleza. Dispone su artículo 1 que

el derecho a vivir en un medio ambiente libre de contaminación, la protección del medio ambiente, la preservación de la naturaleza y la conservación del patrimonio ambiental se regularán por las disposiciones de esta ley, sin perjuicio de lo que otras normas legales establezcan sobre la materia.

Entre otras materias, la Ley 19.300 establece el deber del Estado de facilitar la participación ciudadana, permitir el acceso a la información ambiental y promover campañas educativas destinadas a la protección del medio ambiente, así como también contempla las vías de acceso a la justicia en materia ambiental. Por tanto, como regulación del medio ambiente libre de contaminación, la participación ciudadana es un deber para el Estado, que se entiende forma parte del derecho a vivir en un medio ambiente libre de contaminación, y constituye también una norma especial respecto a la Ley 20.500, sobre Asociaciones y Participación Ciudadana en la Gestión Pública, que en 2011 estableció un nuevo marco normativo general en materia de participación ciudadana.

Al respecto, el derecho internacional ha establecido un modelo predominante a partir de la comprensión de la participación ciudadana a la luz de la Declaración de Río de 1992, en la que se entrelazaron y establecieron tres mecanismos o instrumentos relevantes en la toma de decisiones ambientales, esto es, el acceso a la información, la participación ciudadana y el acceso a la justicia.

En este contexto, el 9 de enero de 2020, el Ejecutivo presentó el proyecto de ley marco de cambio climático para «que regule la institucionalidad del cambio climático y los instrumentos que permitan hacer la gestión del mismo». ${ }^{2}$ Sin embargo, una de las principales críticas que se ha formulado contra el proyecto de ley es que, si bien reconoce el derecho

2 Boletín I3.I9I-I2, Proyecto de ley, iniciado en mensaje de S. E. el presidente de la República, que fija ley marco de cambio climático, p. 6. 
a la participación ciudadana (artículo 31), este se encontraría desprovisto de contenido normativo, con lo que deja su regulación totalmente a nivel reglamentario, o establecido a nivel programático. ${ }^{3}$

El presente artículo persigue analizar si el proyecto de ley marco de cambio climático desarrolla mecanismos de participación ciudadana suficientemente regulados ante las exigencias de participación ambiental ciudadana consagradas a nivel constitucional y legal.

\section{LA PARTICIPACIÓN CIUDADANA}

Como señala Ezio Costa, ${ }^{4}$ el concepto de participación es uno equívoco, sobre el cual hay consenso respecto a sus bondades, pero no en cuanto a su contenido.

En materia ambiental, el disenso a nivel nacional sobre el concepto es aún mayor. Si bien no se ha planteado en forma abierta, la discusión se ha dado solapadamente a propósito del debate sobre si el Estado de Chile debe suscribir y ratificar el Acuerdo Regional sobre el Acceso a la Información, la Participación Pública y el Acceso a la Justicia en Asuntos Ambientales en América Latina y el Caribe, conocido como Acuerdo de Escazú.

En efecto, quienes promueven que el Estado suscriba el Acuerdo de Escazú postulan que el acceso a la información, la participación pública y el acceso a la justicia en asuntos ambientales son, en sí mismos, derechos humanos. Para ello aducen distintos motivos, entre los que podemos destacar:

Primero, que, como lo señala el preámbulo del Acuerdo de Escazú, este es un tratado internacional de derechos humanos, que viene a consagrar y proteger los derechos de acceso a la información, la participación pública y el acceso a la justicia en asuntos ambientales, y que se inserta dentro del sistema interamericano de protección de los derechos humanos. ${ }^{5}$

3 Monserrat Madariaga Gómez de Cuenca, «Participación ciudadana en el proyecto de ley marco de cambio climático», Observatorio Ley de Cambio Climático para Chile, 9 de junio de 2020, https://leycambioclimatico.cl/policy-brief-participacion-ciudadana-en-el-proyecto-de-ley-marco-de-cambio-climatico.

4 Ezio Costa Cordella, Participación ciudadana: Conceptos generales, deliberación y medio ambiente (Santiago: Der, 2020), I-I2.

5 El prefacio del Acuerdo de Escazú señala expresamente, además, que «este Acuerdo Regional es un instrumento jurídico pionero en materia de protección ambiental, pero también es un tratado de derechos humanos» (página 9). 
Segundo, que existiría un acervo normativo en materia de derechos humanos ambientales en América Latina y el Caribe, que ha adquirido rango constitucional, y que se encuentra articulado por la doctrina y la jurisprudencia de la Corte Interamericana de Derechos Humanos.

Tercero, que el artículo 3 del Acuerdo consagra expresamente el principio pro persona. En palabras de la jurista argentina Mónica Pinto:

El principio pro homine [actualmente denominado pro persona] es un criterio hermenéutico que informa todo el derecho de los derechos humanos, en virtud del cual se debe acudir a la norma más amplia, o a la interpretación más extensiva, cuando se trata de reconocer derechos protegidos e, inversamente, a la norma o a la interpretación más restringida cuando se trata de establecer las restricciones permanentes al ejercicio de los derechos humanos. ${ }^{6}$

Cuarto, que el artículo 4 del Acuerdo de Escazú consagra expresamente en su número 8 que cada parte avanzará a la adopción de la interpretación más favorable al pleno goce y respeto de los derechos de acceso, para la implementación del Acuerdo.

Quinto, que Escazú es un tratado internacional para la aplicación del Principio 10 de la Declaración de Río sobre el medio ambiente y el desarrollo.

Sexto, que Escazú tiene como antecedente la «Declaración sobre la aplicación del Principio 10 de la Declaración de Río sobre el Medio Ambiente y el Desarrollo», impulsada por diez Gobiernos de América Latina y el Caribe en la Conferencia de las Naciones Unidas sobre el Desarrollo Sostenible, celebrada en Río de Janeiro del 20 al 22 de junio de 2012, que reafirmaban el compromiso con los derechos de acceso a la información, participación y justicia en asuntos ambientales; manifestaban su voluntad de avanzar hacia un instrumento regional que promoviera su cabal aplicación, y solicitaban el apoyo de la Comisión Económica para América Latina y el Caribe para que actuara como secretaría técnica.

Por otra parte, hay quienes refutan la calidad de derechos humanos de estos derechos de acceso, amparados en los siguientes argumentos:

6 Mónica Pinto, «El principio pro homine: Criterios de hermenéutica y pautas para la regulación de los derechos humanos», en La aplicación de los tratados sobre derechos humanos por los tribunales locales, comp. por Martín Abregú (Buenos Aires: Centro de Estudios Legales y Sociales, I997), I63-172. 
Primero, el preámbulo del Acuerdo de Escazú no señala que este sea un tratado de derechos humanos. Sí lo hace Alicia Bárcena, secretaria ejecutiva de la Comisión Económica para América Latina y el Caribe (Cepal), en el prefacio del texto publicado por Cepal del Acuerdo de Escazú, pero tal prefacio no es parte integrante del texto de Escazú, y por tanto no puede atribuirle al tratado una categoría que no tiene.

Segundo, la Declaración de Río sobre el Medio Ambiente y el Desarrollo de 1992 es un instrumento internacional no vinculante para los Estados, es decir, en sí mismo no contiene ni impone obligaciones internacionales.

Tercero, el Principio 10 de la Declaración de Río sobre el Medio Ambiente y el Desarrollo establece:

El mejor modo de tratar las cuestiones ambientales es con la participación de todos los ciudadanos interesados, en el nivel que corresponda. En el plano nacional, toda persona deberá tener acceso adecuado a la información sobre el medio ambiente de que dispongan las autoridades públicas, incluida la información sobre los materiales y las actividades que ofrecen peligro en sus comunidades, así como la oportunidad de participar en los procesos de adopción de decisiones. Los Estados deberán facilitar y fomentar la sensibilización y la participación del público poniendo la información a disposición de todos. Deberá proporcionarse acceso efectivo a los procedimientos judiciales y administrativos, entre estos el resarcimiento de daños y los recursos pertinentes.

Cuarto, de la sola lectura del Principio 10, salta a la vista que las palabras utilizadas no se refieren a la creación de derechos, ni menos de rango de derechos humanos. Así, por ejemplo, señala: «El mejor modo de tratar las cuestiones ambientales [...]», con lo que queda claramente plasmado que los derechos de acceso son derechos instrumentales para garantizar el derecho humano a un medio ambiente sano, mas no constituyen un derecho humano en sí mismo. En el mismo sentido, cuando señala: «En el plano nacional, toda persona deberá tener acceso [...]», establece un deber de los Estados para consagrar legalmente los derechos de acceso, pero la consagración de tales derechos en la legislación, si bien puede constituir un desarrollo legal de instrumentos que garantizan un derecho humano - en este caso, el derecho a vivir en un medio ambiente libre de contaminación-, no lo transforma en un derecho humano en sí mismo.

Quinto, la Corte Interamericana de Derechos Humanos ha señalado expresamente que la participación pública es un derecho instrumental o de procedimiento, al establecer que «Con respecto a asuntos ambientales, la participación representa un mecanismo para in- 
tegrar las preocupaciones y el conocimiento de la ciudadanía en las decisiones de políticas públicas que afectan al medio ambiente». ${ }^{7}$

Quinto, la dignidad de los seres humanos es la fuente de los derechos humanos. No la consagración positiva en un tratado o instrumento internacional.

Sexto, si Escazú es la concreción de los derechos de acceso contenidos en el Principio 10 de la Declaración de Río, y ese principio no consagra ni eleva a la categoría de derecho humano los derechos de acceso, no se entiende cómo puede la concreción de un principio que establece instrumentos transformarse o mutar en derechos humanos. Es el reflejo de la vieja máxima de la lógica «nadie puede dar lo que no tiene».

Definir si los derechos de acceso son derechos humanos en sí mismos o derechos instrumentales que pueden consagrarse a nivel legal y que aseguran la consecución de otros derechos, excede largamente al propósito de este artículo. Luego utilizaremos en este trabajo el concepto de participación ciudadana de Castellà, quien la entiende como «concurrir en el proceso de adopción de decisiones de los poderes públicos por parte de los ciudadanos», ${ }^{8}$ pues nos parece que se adecúa de mejor manera a la participación ciudadana en materia ambiental, conforme lo ha desarrollado la legislación ambiental chilena. En el mismo sentido, Lara y Letelier la conceptualizan como «un medio que permite que el ciudadano forme parte de la definición, ejecución, control y evaluación de las decisiones de gobierno, siempre y cuando exista la voluntad del ciudadano de ejercer ese derecho». ${ }^{9}$

En efecto, a nuestro juicio la legislación ambiental chilena ha entendido la participación ciudadana como una forma de concurrir por parte de los ciudadanos a los procedimientos administrativos para la elaboración y dictación de una serie de instrumentos de gestión ambiental.

Puede ser que esta definición no satisfaga a muchos, pues pone el énfasis solo en concurrir al procedimiento, mientras algunos buscan destacar la capacidad de incidir en la toma de decisiones o la capacidad de deliberar que le arrogan a la participación; o que algunos nos achaquen que solo nos referimos a la participación ciudadana institucionalizada, o administrativa, que vendrían siendo apenas vertientes respecto de un concepto

7 Corte Interamericana de Derechos Humanos, «Opinión consultiva OC-23/17 de I5 de noviembre de 2017 solicitada por la República de Colombia», párr. 228 (el destacado es nuestro).

8 Josep María Castellà, Los derechos constitucionales de participación política en la Administración Pública (Barcelona: Cedec, 200I).

9 Martín Lara y Diego Letelier, «Mecanismos de participación ciudadana en el Sistema de Evaluación de Impacto Ambiental chileno», Revista de Gestión Pública 6, n. ${ }^{2} 2$ (20I7): 287. 
de participación mucho más amplio, que tiene que ver con la participación a través de las elecciones periódicas y el plebiscito, por ejemplo; pero creemos que es el concepto que mejor se adecúa al desarrollo normativo ambiental chileno.

La legislación ambiental chilena establece una serie de instrumentos de gestión ambiental, a saber, el Sistema de Evaluación de Impacto Ambiental, la Evaluación Ambiental Estratégica, las normas de calidad - ya sea primarias o secundarias-, las normas de emisión, los planes de prevención y de descontaminación, los planes de manejo, las metas de recolección y valorización de la responsabilidad extendida del productor, por nombrar los principales; y regula el procedimiento administrativo para su elaboración y dictación, dentro de cuyos aspectos se regula la participación ciudadana, así como los medios de impugnación administrativa especial o general, y en sede judicial especial.

A continuación, abordaremos el desarrollo de la participación ciudadana en la legislación ambiental nacional.

\section{LA PARTICIPACIÓN CIUDADANA EN LA LEGISLACIÓN AMBIENTAL CHILENA}

En los años recientes, la legislación ambiental chilena ha tenido un creciente desarrollo. Así, en la última década han sido dictadas la Ley 20.417, que crea el Ministerio, el Servicio de Evaluación Ambiental, y la Superintendencia del Medio Ambiente; la Ley 20.473, que Otorga, Transitoriamente, las Facultades Fiscalizadoras y Sancionadoras que Indica a la Comisión Señalada en el Artículo 86 de la Ley 19.300; la Ley 20.600, que Crea los Tribunales Ambientales; la Ley 20.780, Reforma Tributaria que Modifica el Sistema de Tributación de la Renta e Introduce Diversos Ajustes en el Sistema Tributario - que introdujo por primera vez los llamados impuestos verdes-; la Ley 20.920, que Establece el Marco para la Gestión de Residuos, la Responsabilidad Extendida del Productor y Fomento al Reciclaje; la Ley 21.100, que Prohíbe la Entrega de Bolsas Plásticas de Comercio en todo el Territorio Nacional; la Ley 21.202, que Modifica Diversos Cuerpos Legales con el Objetivo de Proteger los Humedales Urbanos; y la Ley 21.210, que Moderniza la Legislación Tributaria (en lo que respecta a la modernización de los impuestos verdes).

Además de lo anterior, actualmente se encuentra en discusión en el Congreso Nacional un importante número de proyectos de ley que vienen a complementar el entramado institucional y la normativa ambiental que nos rige, como el proyecto de ley que moderniza el Sistema de Evaluación de Impacto Ambiental (Boletín 12.714-12); el que crea el Servicio de Biodiversidad y Áreas Protegidas y el Sistema Nacional de Áreas Protegidas (Boletín 9.404-12); el proyecto de ley sobre delitos ambientales y daño ambiental (Boletín 12.39812); y el proyecto de ley que modifica la Ley 21.100, a fin de prohibir la entrega y venta de los artefactos plásticos que indica (Boletín 12.641-12), solo por nombrar algúnos ejemplos. 
Tan amplio desarrollo normativo parte del reconocimiento que la Constitución hace a todas las personas del derecho a vivir en un medio ambiente libre de contaminación, en el artículo 19, numeral octavo. Pero quizá el hito que estableció un mayor desarrollo fue la suscripción del Estado de Chile de la Declaración de Río en 1992, en el marco de la Conferencia de las Naciones Unidas sobre el Medio Ambiente y el Desarrollo, que plantea que el mejor modo de tratar las cuestiones ambientales es con la participación de una ciudadanía informada, y que se deberá proporcionar acceso efectivo a los procedimientos judiciales y administrativos, entre estos al resarcimiento de daños y a los recursos pertinentes.

Este fue el marco internacional en que se generó la Ley 19.300 sobre Bases Generales del Medio Ambiente, que es la ley que desarrolla el derecho fundamental en la materia. Así lo estableció el mensaje de la Ley 19.300, que señalaba que «el primer objetivo del presente proyecto de ley es darle un contenido concreto y un desarrollo jurídico adecuado a la garantía constitucional que asegura a todas las personas el derecho a vivir en un medio ambiente libre de contaminación». Así quedó de manifiesto en el artículo 1 de la misma ley. ${ }^{10}$

La Ley 19.300 recogió diversos principios. Uno de los principales, en línea con el Principio 10 de la Declaración de Río, ${ }^{11}$ fue el principio participativo. ${ }^{12}$ Es más, el mensaje de la ley señalaba expresamente que, «para lograr una adecuada protección del medio ambiente, se requiere de la concurrencia de todos los afectados en la problemática». Ello quedó de manifiesto de forma general en el artículo 4, que originalmente disponía: «Es deber del Estado facilitar la participación ciudadana y promover campañas educativas destinadas

10 Ley I9.300, artículo I: «El derecho a vivir en un medio ambiente libre de contaminación, la protección del medio ambiente, la preservación de la naturaleza y la conservación del patrimonio ambiental se regularán por las disposiciones de esta ley, sin perjuicio de lo que otras normas legales establezcan sobre la materia».

11 Declaración de Río sobre el medio ambiente y el desarrollo, Principio ıo: «El mejor modo de tratar las cuestiones ambientales es con la participación de todos los ciudadanos interesados, en el nivel que corresponda. En el plano nacional, toda persona deberá tener acceso adecuado a la información sobre el medio ambiente de que dispongan las autoridades públicas, incluida la información sobre los materiales y las actividades que ofrecen peligro en sus comunidades, así como la oportunidad de participar en los procesos de adopción de decisiones. Los Estados deberán facilitar y fomentar la sensibilización y la participación del público poniendo la información a disposición de todos. Deberá proporcionarse acceso efectivo a los procedimientos judiciales y administrativos, entre éstos el resarcimiento de daños y los recursos pertinentes».

12 Costa Cordella, Participación..., 235. 
a la protección del medio ambiente», al cual después se le intercaló la frase «permitir el acceso a la información ambiental», mediante el artículo 1, numeral segundo, letra a) de la Ley 20.417, de forma que en la actualidad el artículo 4 prescribe: «Es deber del Estado facilitar la participación ciudadana, permitir el acceso a la información ambiental y promover campañas educativas destinadas a la protección del medio ambiente».

No hay que perder de vista, además, que la Ley 19.300 es una ley de bases, es decir, cumple un rol fundamental en orden a la interpretación de los preceptos y conceptos jurídicos que se establezcan en las demás disposiciones y normas que regulen esa actividad (el derecho a vivir en un medio ambiente libre de contaminación), y cumple la función de ser una norma de carácter supletorio frente a regulaciones especiales. ${ }^{13}$

Dado lo señalado, creemos que es evidente que la participación ciudadana, si bien no está positivamente reconocida en el derecho a vivir en un medio ambiente libre de contaminación reconocido en el artículo 19 numeral octavo de la Constitución Política de la República, es parte integrante de ese derecho, en línea con lo que se ha señalado por la Corte Interamericana de Derechos Humanos (CIDH) en su Opinión Consultiva 23/17. ${ }^{14}$

Ahora bien, creemos también evidente que la Ley 19.300, como reguladora del derecho a vivir en un medio ambiente libre de contaminación, desarrolla la participación ciudadana en materia ambiental como una forma de concurrir por parte de los ciudadanos a los procedimientos administrativos para la elaboración y dictación de los instrumentos de gestión ambiental que ella consagra, es decir, la concibe como una participación administrativa, que da derecho a los ciudadanos a interiorizarse de los antecedentes, contenidos y los fundamentos de hecho y de derecho sobre la base de los cuales se adoptan ciertas decisiones, a formular las observaciones en el procedimiento de elaboración y dictación del instrumento de gestión de que se trate, y a reclamar administrativa o judicialmente de la decisión que en definitiva adopte la Administración del Estado.

13 Rosa Gómez González, «Rol e importancia de las leyes de bases en el derecho administrativo chileno», Revista de Derecho (Valdivia) 29, n. ${ }^{\circ} 2$ (2016): 213-228. Señala la autora: «Las leyes de bases dentro del derecho administrativo se han presentado como preceptos que buscan consolidar, unificar e integrar un determinado microsistema, de modo tal que su contenido sea empleado de manera supletoria frente a la aplicación de una ley especial o una colección de leyes. Dentro de sus funciones está servir de sustento a los jueces y legisladores, para que sea considerada por los primeros al momento de resolver algún caso vinculado con la materia específica (herramienta de interpretación judicial) y, por los segundos, a la hora de dictar nuevos preceptos, vinculándolos con aquellas. Finalmente, su principal objeto es dar certeza y seguridad jurídica a los sujetos regulados por el microsistema respectivo».

14 Corte Interamericana de Derechos Humanos, «Opinión Consultiva OC-23/17...». 
En ese sentido, estimamos que el concepto de participación ciudadana en la Ley 19.300 dice relación, como señala Moreno, con

el conjunto de directrices, principios y normas dispuestas por la ley y la autoridad competente que permiten a las personas, naturales y jurídicas, y a las organizaciones sociales y comunitarias afectadas o interesadas en alguna forma por distintos eventos de relevancia ambiental ser incorporadas formalmente al proceso decisional que lleva a la adopción de políticas y medidas de carácter medioambiental, a la autorización de actividades que importan un compromiso ambiental, a la dictación de las regulaciones pertinentes y a la resolución de los conflictos que se presenten. ${ }^{15}$

Para resumir, primero, la Ley 19.300 sobre bases generales del medio ambiente consagra expresamente en su artículo 1 que

el derecho a vivir en un medio ambiente libre de contaminación, la protección del medio ambiente, la preservación de la naturaleza y la conservación del patrimonio ambiental se regularán por las disposiciones de esta ley, sin perjuicio de lo que otras normas legales establezcan sobre la materia.

Segundo, el mensaje de la Ley 19.300 reconoce que «el primer objetivo del presente proyecto de ley es darle un contenido concreto y un desarrollo jurídico adecuado a la garantía constitucional que asegura a todas las personas el derecho a vivir en un medio ambiente libre de contaminación».

Tercero, la Ley 19.300 establece positivamente el deber legal del Estado de facilitar la participación ciudadana en su artículo 4 .

Cuarto, el mismo mensaje de la Ley 19.300 reconoce el principio participativo, señalando al efecto que «el proyecto establece el principio participativo. Este principio es de vital importancia en el tema ambiental, puesto que, para lograr una adecuada protección del medio ambiente, se requiere de la concurrencia de todos los afectados en la problemática».

Quinto, que la Ley 19.300 establece una serie de instrumentos de gestión ambiental, en que desarrolla ya sea en la misma ley, ya sea vía reglamentaria, el procedimiento para su elaboración y dictación, y como parte integrante de ello, los espacios de participación ciudadana que estos contemplan.

15 Carlos Moreno Santander, Participación ciudadana en la Ley 19:300, sobre Bases Generales del Medio Ambiente (Santiago: Lexis Nexis, 2004), 47. 
Sexto, que, por tanto, la participación ciudadana que consagra la legislación ambiental chilena se adecúa al concepto de participación administrativa, al permitir que los ciudadanos concurran, se interioricen y manifiesten sus observaciones en los procedimientos administrativos de elaboración y dictación de los distintos instrumentos de gestión ambiental, para luego ejercer los recursos administrativos y judiciales que estimen pertinente frente a la decisión que adopte la Administración del Estado.

Tan evidente es lo anterior que, al hacer un análisis de los instrumentos de gestión ambiental establecidos en la legislación ambiental (tabla 1), en especial en la Ley 19.300 y en la Ley 20.920, de los siete instrumentos de gestión ambiental, solo tres contemplan mecanismos de participación ambiental ciudadana (PAC) o consulta pública en la misma ley; del resto, no obstante no establecerlo el legislador, en virtud del artículo 4 de la Ley 19.300, es establecido o desarrollado a nivel reglamentario.

Tabla 1. Mecanismos de participación ambiental ciudadana en instrumentos de gestión ambiental

\begin{tabular}{|c|c|c|c|}
\hline $\begin{array}{l}\text { Instrumento de gestión } \\
\text { ambiental }\end{array}$ & $\begin{array}{l}\text { Ley que } \\
\text { establece el } \\
\text { instrumento } \\
\end{array}$ & $\begin{array}{l}\text { Normativa que } \\
\text { establece la } \\
\text { PAC }\end{array}$ & Regulación de la PAC \\
\hline $\begin{array}{l}\text { Servicio de Evaluación } \\
\text { de Impacto Ambiental } \\
\text { (SEIA) }\end{array}$ & Ley 19.300 & $\begin{array}{l}\text { Párrafo tercero, } \\
\text { Ley } 19.300\end{array}$ & $\begin{array}{l}\text { DS 40/2013, } \\
\text { reglamento del SEIA }\end{array}$ \\
\hline $\begin{array}{l}\text { Normas de calidad } \\
\text { ambiental }\end{array}$ & Ley 19.300 & No establece & $\begin{array}{l}\text { DS } 38 / 2013 \text {, reglamento de } \\
\text { normas de calidad y normas } \\
\text { de emisión }\end{array}$ \\
\hline Normas de emisión & Ley 19.300 & No establece & $\begin{array}{l}\text { DS } 38 / 2013 \text {, reglamento de } \\
\text { normas de calidad y normas } \\
\text { de emisión }\end{array}$ \\
\hline $\begin{array}{l}\text { Evaluación Ambiental } \\
\text { Estratégica (EAE) }\end{array}$ & Ley 19.300 & $\begin{array}{l}\text { Artículo } 7 \\
\text { letra c) }\end{array}$ & $\begin{array}{l}\text { DS 32/2015, reglamento de } \\
\text { Evaluación Ambiental } \\
\text { Estratégica }\end{array}$ \\
\hline $\begin{array}{l}\text { Planes de Prevención } \\
\text { o Descontaminación } \\
\text { Atmosférica (PPDA) }\end{array}$ & Ley 19.300 & No establece & $\begin{array}{l}\text { DS 39/2013, reglamento de } \\
\text { Planes de Prevención y Des- } \\
\text { contaminación Ambiental }\end{array}$ \\
\hline Planes de manejo & Ley 19.300 & No establece & \\
\hline $\begin{array}{l}\text { Decreto Supremo que } \\
\text { establece metas de reco- } \\
\text { lección y valorización de } \\
\text { los productos prioritarios } \\
\text { de la Ley de Responsa- } \\
\text { bilidad Extendida del } \\
\text { Productor (REP) }\end{array}$ & Ley 20.920 & $\begin{array}{l}\text { Artículo } 4 \\
\text { letra c) }\end{array}$ & $\begin{array}{l}\text { DS 8/2017, reglamento que } \\
\text { regula el procedimiento de } \\
\text { elaboración de los decretos } \\
\text { supremos establecidos en la } \\
\text { Ley } 20.920\end{array}$ \\
\hline
\end{tabular}


Cabe preguntarse, ¿̨es necesario que la regulación de la participación ciudadana esté establecida a nivel legal? ¿ $\mathrm{O}$, por el contrario, basta que se establezca que deberá contemplarse un espacio de participación ciudadana, pero que este en definitiva se regule en el reglamento?

La respuesta a estas preguntas - a mi juicio- es sencilla conforme a nuestra Constitución Política, pero depende de la respuesta a otra pregunta anterior, que ya esbozamos: ¿ es la participación ciudadana en materia ambiental un derecho humano en sí mismo?

Como ya dijimos, hay quienes estiman que la participación ciudadana es parte integrante de la regulación del derecho a vivir en un medio ambiente libre de contaminación, pero eso no hace que sea un derecho fundamental en sí mismo. Puede ser un derecho de consagración legal, instrumental para la consecución de un derecho humano, pero no un derecho humano. Por otro lado, hay quienes entienden que los derechos de acceso en materia ambiental, entre los cuales está la participación ciudadana (participación pública, según la nomenclatura de Escazú), son un derecho humano en sí mismo.

Como ya hemos dicho, no es el propósito de este trabajo dar respuesta a esa pregunta, pero la respuesta que se dé es esencial para determinar el rango que debe tener la normativa que lo regule.

Al respecto, la Constitución otorga al presidente de la República la atribución especial de «ejercer la potestad reglamentaria, en todas aquellas materias que no sean propias del dominio legal, sin perjuicio de la facultad de dictar los demás reglamentos, decretos e instrucciones que crea convenientes para la ejecución de las leyes» (artículo 32, numeral sexto). Es decir, la Constitución permite que el presidente, en el ejercicio de su potestad, dicte reglamentos que regulen la ejecución de las leyes. Y si puede hacerlo por atribución propia, más aún puede hacerlo si el legislador establece que el presidente de la República deberá dictar un reglamento que regule cierta materia con algunos mínimos.

Mas, para quienes estiman que la participación ciudadana en materia ambiental es un derecho humano, este solo puede ser regulado por el legislador, en virtud de lo establecido en el artículo 19 numeral 26. ${ }^{\circ}$ de la Constitución, que establece la reserva de ley en materia de derechos fundamentales al señalar:

Los preceptos legales que por mandato de la Constitución regulen o complementen las garantías que esta establece o que las limiten en los casos en que ella lo autoriza, no podrán afectar los derechos en su esencia, ni imponer condiciones, tributos o requisitos que impidan su libre ejercicio. 
Por tanto, de la forma en que se conciban los derechos de acceso, emana consecuencialmente la forma en que estos deben ser regulados. Si uno estima que es un derecho humano, solo cabría su regulación por ley, por aplicación del artículo 19 numeral 26. ${ }^{\circ}$ en relación con el artículo 32, numeral sexto, ambos de la Constitución. Mas, si uno considera que es un derecho de carácter instrumental, como en la especie lo ha hecho toda la normativa ambiental, perfectamente esta puede ser regulada por la potestad reglamentaria del presidente de la República. Creemos que esa es la interpretación que se ha dado en la normativa ambiental chilena, ya que si no fuese así, todas las regulaciones en el ámbito reglamentario serían derechamente inconstitucionales.

\section{LA PARTICIPACIÓN CIUDADANA EN EL PROYECTO DE LEY QUE FIJA LA LEY MARCO DE CAMBIO CLIMÁTICO}

El proyecto de ley marco de cambio climático tiene por objeto, en palabras del Ejecutivo, ${ }^{16}$ recogidas por la Corte Suprema en su informe del proyecto de ley, ${ }^{17}$ «crear el marco jurídico que permita asignar responsabilidades específicas para la implementación de medidas de mitigación y adaptación al cambio climático».

Por su parte, el proyecto reconoce expresamente el derecho a la participación ciudadana, entendida como participación administrativa. Su artículo 31 lo establece para «la elaboración, revisión y actualización de los instrumentos de gestión del cambio climático». Además, en el proyecto se hacen otras referencias a la participación ciudadana, aunque corresponden más bien a normas de naturaleza programática. Así, se establece el principio de transversalidad (artículo 2), el cual prescribe un deber estatal de «promover [...] la participación del sector privado, la academia y la sociedad civil». Por otra parte, el inciso tercero del artículo 13 establece el deber de tener «especial consideración con los sectores más vulnerables, aplicando un enfoque de género y procurando facilitar la participación de dichos sectores».

Ahora bien, el proyecto de ley contempla una serie de instrumentos de gestión del cambio climático. Estos se dividen en:

- Instrumentos de gestión a nivel nacional: La Estrategia Climática de Largo Plazo, la Contribución Determinada a Nivel Nacional, los Planes Sectoriales de Mitigación y Adaptación, y las Normas de Emisión de Gases de Efecto Invernadero, todos los cuales incluyen etapas formales de consulta pública,

16 Boletín I3.I9I-I2, Proyecto de ley que fija la ley marco de cambio climático, p. 8.

17 Corte Suprema, «Oficio I38-2020, Informe proyecto de Ley 26-2020», 27 de julio de 2020. 
en línea con el concepto de participación ciudadana que recoge la legislación ambiental chilena, esto es, como la capacidad de concurrir en el proceso de adopción de decisiones de los poderes públicos por parte de los ciudadanos.

- Instrumentos de gestión a nivel regional: En este nivel podemos encontrar los Planes de Acción Regional de Cambio Climático y los Planes Estratégicos de Recursos Hídricos de Cuencas, ninguno de los cuales contempla espacios de participación ciudadana.

A continuación, exponemos en la tabla 2 cómo se regula la participación ciudadana respecto de cada uno de estos instrumentos. Para ello, individualizaremos el instrumento de gestión, la ley que establece el instrumento (en este caso todos son establecidos en el proyecto de ley marco de cambio climático), la normativa que establece la participación ciudadana, así como la normativa donde se contempla la regulación de esa participación, en caso de que la haya; y, por último, incluimos la redacción de la norma.

Tabla 2. Regulación de participación ambiental ciudadana en los instrumentos de gestión del cambio climático

\begin{tabular}{|l|l|l|l|l|}
$\begin{array}{l}\text { Instrumento } \\
\text { de gestión } \\
\text { ambiental }\end{array}$ & $\begin{array}{l}\text { Ley que } \\
\text { establece el } \\
\text { instrumento }\end{array}$ & $\begin{array}{l}\text { Normativa } \\
\text { que establece } \\
\text { la PAC }\end{array}$ & $\begin{array}{l}\text { Regulación de } \\
\text { la PAC }\end{array}$ & Redacción de la norma \\
\hline $\begin{array}{l}\text { Estrategia } \\
\text { climática de } \\
\text { largo plazo }\end{array}$ & $\begin{array}{l}\text { Proyecto de } \\
\text { ley marco } \\
\text { de cambio } \\
\text { climático }\end{array}$ & $\begin{array}{l}\text { Artículo 5, } \\
\text { inciso tercero } \\
\text { del proyecto } \\
\text { de ley marco } \\
\text { de cambio } \\
\text { climático }\end{array}$ & $\begin{array}{l}\text { Reglamento } \\
\text { del Ministerio } \\
\text { de Medio } \\
\text { Ambiente }\end{array}$ & $\begin{array}{l}\text { «El procedimiento para la elaboración } \\
\text { de la Estrategia Climática de Largo Plazo } \\
\text { estará a cargo del Ministerio del Medio } \\
\text { Ambiente, en coordinación con las autori- } \\
\text { dades sectoriales señaladas en el artículo } \\
\text { 16 y ministerios competentes. Deberá } \\
\text { contemplar, al menos, una etapa de con- } \\
\text { sulta pública que tendrá una duración de } \\
\text { sesenta días hábiles; el informe previo del } \\
\text { Comité Científico Asesor para el Cambio } \\
\text { Climático; y el pronunciamiento del Con- } \\
\text { sejo de Ministros para la Sustentabilidad } \\
\text { yel Cambio Climático, previa consulta al } \\
\text { Consejo establecido en el artículo 19 de } \\
\text { esta ley». }\end{array}$ \\
\hline
\end{tabular}




\begin{tabular}{|c|c|c|c|c|}
\hline $\begin{array}{l}\text { Contribución } \\
\text { Determinada } \\
\text { a Nivel } \\
\text { Nacional }\end{array}$ & $\begin{array}{l}\text { Proyecto de } \\
\text { ley marco } \\
\text { de cambio } \\
\text { climático }\end{array}$ & $\begin{array}{l}\text { Artículo } 7 \\
\text { inciso cuarto } \\
\text { del proyecto } \\
\text { de ley marco } \\
\text { de cambio } \\
\text { climático }\end{array}$ & $\begin{array}{l}\text { Reglamento } \\
\text { del Ministerio } \\
\text { de Medio } \\
\text { Ambiente }\end{array}$ & $\begin{array}{l}\text { «Un reglamento expedido por decreto } \\
\text { supremo del Ministerio del Medio Am- } \\
\text { biente, suscrito además por el Ministro de } \\
\text { Hacienda, establecerá el procedimiento } \\
\text { para la elaboración o actualización de la } \\
\text { Contribución Determinada a Nivel Nacio- } \\
\text { nal, según corresponda. } \\
\text { El procedimiento será coordinado } \\
\text { por el Ministerio del Medio Ambiente con } \\
\text { apoyo del Ministerio de Relaciones Exte- } \\
\text { riores, y deberá contemplar, al menos, la } \\
\text { participación de las autoridades sectoriales } \\
\text { que corresponda; una etapa de consulta } \\
\text { pública que tendrá una duración de treinta } \\
\text { días hábiles; el informe previo del Comité } \\
\text { Científico Asesor para el Cambio Climá- } \\
\text { tico; y, el pronunciamiento del Consejo } \\
\text { de Ministros para la Sustentabilidad y el }\end{array}$ \\
\hline $\begin{array}{l}\text { Planes } \\
\text { Sectoriales de } \\
\text { Mitigación } \\
\text { al Cambio } \\
\text { Climático }\end{array}$ & $\begin{array}{l}\text { Proyecto de } \\
\text { ley marco } \\
\text { de cambio } \\
\text { climático }\end{array}$ & $\begin{array}{l}\text { Artículo 8, } \\
\text { inciso cuarto } \\
\text { del proyecto } \\
\text { de ley marco } \\
\text { de cambio } \\
\text { climático }\end{array}$ & $\begin{array}{l}\text { Reglamento } \\
\text { del Ministerio } \\
\text { de Medio } \\
\text { Ambiente }\end{array}$ & $\begin{array}{l}\text { «Un reglamento expedido por decreto su- } \\
\text { premo del Ministerio del Medio Ambiente, } \\
\text { suscrito además por el Ministro de Ha- } \\
\text { cienda, establecerá el procedimiento para } \\
\text { la elaboración, revisión y actualización de } \\
\text { los Planes Sectoriales de Mitigación. Dicho } \\
\text { procedimiento contemplará, al menos, la } \\
\text { participación de las autoridades sectoriales } \\
\text { competentes, una etapa de consulta públi- } \\
\text { ca que tendrá una duración de treinta días } \\
\text { hábiles, y el pronunciamiento del Consejo } \\
\text { de Ministros para la Sustentabilidad y el } \\
\text { Cambio Climático». }\end{array}$ \\
\hline $\begin{array}{l}\text { Planes } \\
\text { Sectoriales de } \\
\text { Adaptación } \\
\text { al Cambio } \\
\text { Climático }\end{array}$ & $\begin{array}{l}\text { Proyecto de } \\
\text { ley marco } \\
\text { de cambio } \\
\text { climático }\end{array}$ & $\begin{array}{l}\text { Artículo } \\
9, \text { incisos } \\
\text { segundo y } \\
\text { tercero del } \\
\text { proyecto de } \\
\text { ley marco } \\
\text { de cambio } \\
\text { climático }\end{array}$ & $\begin{array}{l}\text { Reglamento } \\
\text { del Ministerio } \\
\text { de Medio } \\
\text { Ambiente }\end{array}$ & $\begin{array}{l}\text { «Un reglamento expedido por decreto su- } \\
\text { premo del Ministerio del Medio Ambiente, } \\
\text { suscrito además por el Ministro de Hacien- } \\
\text { da, establecerá el procedimiento para la } \\
\text { elaboración, revisión y actualización de los } \\
\text { Planes Sectoriales de Adaptación. } \\
\text { La elaboración e implementación } \\
\text { de los planes sectoriales será de respon- } \\
\text { sabilidad de las autoridades sectoriales } \\
\text { señaladas, las que deberán colaborar con } \\
\text { los organismos con competencia en la ma- } \\
\text { teria. Dicho procedimiento será coordina- } \\
\text { do por el Ministerio del Medio Ambiente, } \\
\text { y contemplará, al menos, una etapa de con- } \\
\text { sulta pública que tendrá una duración de } \\
\text { treinta días hábiles, y el pronunciamiento } \\
\text { del Consejo de Ministros para la Sustenta- } \\
\text { bilidad y el Cambio Climático». }\end{array}$ \\
\hline
\end{tabular}




\begin{tabular}{|c|c|c|c|c|}
\hline $\begin{array}{l}\text { Reporte } \\
\text { de Acción } \\
\text { Nacional } \\
\text { de Cambio } \\
\text { Climático }\end{array}$ & $\begin{array}{l}\text { Proyecto de } \\
\text { ley marco } \\
\text { de cambio } \\
\text { climático }\end{array}$ & $\begin{array}{l}\text { No contempla } \\
\text { PAC }\end{array}$ & & \\
\hline $\begin{array}{l}\text { Planes de } \\
\text { Acción } \\
\text { Regional } \\
\text { de Cambio } \\
\text { Climático }\end{array}$ & $\begin{array}{l}\text { Proyecto de } \\
\text { ley marco } \\
\text { de cambio } \\
\text { climático }\end{array}$ & $\begin{array}{l}\text { No contempla } \\
\text { PAC }\end{array}$ & & \\
\hline $\begin{array}{l}\text { Planes } \\
\text { Estratégicos } \\
\text { de Recursos } \\
\text { Hídricos en } \\
\text { Cuencas }\end{array}$ & $\begin{array}{l}\text { Proyecto de } \\
\text { ley marco } \\
\text { de cambio } \\
\text { climático }\end{array}$ & $\begin{array}{l}\text { No contempla } \\
\text { PAC }\end{array}$ & & \\
\hline $\begin{array}{l}\text { Normas de } \\
\text { emisión de } \\
\text { gases de efecto } \\
\text { invernadero }\end{array}$ & $\begin{array}{l}\text { Proyecto de } \\
\text { ley marco } \\
\text { de cambio } \\
\text { climático }\end{array}$ & $\begin{array}{l}\text { Artículo } 13, \\
\text { inciso tercero } \\
\text { del proyecto } \\
\text { de ley marco } \\
\text { de cambio } \\
\text { climático }\end{array}$ & $\begin{array}{l}\text { Reglamento } \\
\text { del Ministerio } \\
\text { de Medio } \\
\text { Ambiente }\end{array}$ & $\begin{array}{l}\text { «Un reglamento del Ministerio del Medio } \\
\text { Ambiente, suscrito además por el Minis- } \\
\text { tro de Hacienda, detallará el contenido } \\
\text { mínimo de los decretos referidos en el } \\
\text { presente artículo, así como el procedimien- } \\
\text { to de elaboración y revisión de los mismos. } \\
\text { Dicho procedimiento deberá contar con, } \\
\text { a lo menos, la siguientes etapas: análisis } \\
\text { técnico y económico, consulta a organis- } \\
\text { mos y entidades, públicas y privadas, una } \\
\text { etapa de participación ciudadana y análisis } \\
\text { de observaciones, consulta al Consejo } \\
\text { Nacional para la Sustentabilidad y el Cam- } \\
\text { bio Climático, informe previo del Comité } \\
\text { Científico Asesor para el Cambio Climático } \\
\text { y el pronunciamiento del Consejo de Mi- } \\
\text { nistros para la Sustentabilidad y el Cambio } \\
\text { Climático, definiendo además, los plazos y } \\
\text { formalidades del procedimiento». }\end{array}$ \\
\hline
\end{tabular}

Como puede apreciarse, el proyecto de ley marco de cambio climático, si bien establece la participación ciudadana en los instrumentos de gestión del cambio climático, no lo hace en todos. Llama la atención que la establece para los instrumentos a nivel nacional, mas no para los de nivel regional o local, aunque nada obsta que, como en otros instrumentos de gestión ambiental, como las normas de calidad o emisión, por reglamento se establezcan procedimientos de participación ciudadana, en virtud de la potestad reglamentaria del presidente de la República, y dando cumplimiento al deber prescrito en el artículo 4 de la Ley 19.300. 
En cuanto al contenido del concepto de participación ciudadana, si bien no contempla una definición ni fija un estándar, se debe entender que establece la participación ciudadana como participación administrativa, en línea con el desarrollo que de la participación ciudadana ha realizado el resto de la legislación ambiental chilena. Es cierto que el proyecto no establece las formas o niveles mínimos de participación ciudadana y que delega completamente su regulación al reglamento, pero esto - a nuestro juicio- es porque el proyecto asume que la participación ciudadana es un derecho instrumental al derecho fundamental de vivir en un medio ambiente libre de contaminación, no un derecho humano en sí mismo, y lo concibe, por tanto, como la posibilidad de concurrir en el proceso de adopción de decisiones de los poderes públicos por parte de los ciudadanos, es decir, como participación administrativa.

\section{CONCLUSIONES}

De manera sucinta, cabe mencionar las siguientes conclusiones del presente artículo:

Primero, el proyecto de ley marco de cambio climático contempla espacios de participación ciudadana.

Segundo, el proyecto, si bien establece la participación ciudadana en los instrumentos de gestión del cambio climático, no lo hace en todos.

Tercero, en cuanto al contenido del concepto de participación ciudadana, si bien no contempla una definición ni fija un estándar, se debe entender que establece la participación ciudadana como participación administrativa, en línea con el desarrollo que de la participación ciudadana ha realizado el resto de la legislación ambiental chilena.

Cuarto, el proyecto no establece las formas o niveles mínimos de participación ciudadana, y delega completamente la regulación de esta al reglamento.

Quinto, el proyecto asume que la participación ciudadana es un derecho instrumental al derecho fundamental de vivir en un medio ambiente libre de contaminación, y no un derecho humano en sí mismo, y lo concibe, por tanto, como la posibilidad de concurrir en el proceso de adopción de decisiones de los poderes públicos por parte de los ciudadanos - es decir, como participación administrativa-, en línea con el desarrollo que de la participación ciudadana ha realizado la legislación ambiental chilena.

Sexto, como se aprecia en la tabla 3, que presenta un resumen de los instrumentos de gestión ambiental que establecen distintas leyes en materia ambiental, su fuente normativa y su regulación, la participación ciudadana en la legislación ambiental chilena está mayoritariamente regulada a través de la potestad reglamentaria del presidente de la República. 
Tabla 3. Resumen de los instrumentos de gestión ambiental que establecen distintas leyes en materia ambiental, fuente normativa y regulación de la participación ambiental ciudadana

\begin{tabular}{|c|c|c|c|}
\hline $\begin{array}{l}\text { Instrumento de gestión } \\
\text { ambiental }\end{array}$ & $\begin{array}{l}\text { Ley que } \\
\text { establece el } \\
\text { instrumento }\end{array}$ & $\begin{array}{l}\text { Normativa que } \\
\text { establece la } \\
\text { PAC }\end{array}$ & Regulación de la PAC \\
\hline $\begin{array}{l}\text { Servicio de Evaluación } \\
\text { de Impacto Ambiental } \\
\text { (SEIA) }\end{array}$ & Ley 19.300 & $\begin{array}{l}\text { Párrafo 3, Ley } \\
19.300\end{array}$ & Reglamento del SEIA \\
\hline $\begin{array}{l}\text { Normas de calidad } \\
\text { ambiental }\end{array}$ & Ley 19.300 & No establece & $\begin{array}{l}\text { Reglamento Normas de } \\
\text { Calidad Ambiental }\end{array}$ \\
\hline Normas de emisión & Ley 19.300 & No establece & $\begin{array}{l}\text { Reglamento Normas de } \\
\text { Calidad Ambiental }\end{array}$ \\
\hline $\begin{array}{l}\text { Evaluación Ambiental } \\
\text { Estratégica }\end{array}$ & Ley 19.300 & $\begin{array}{l}\text { Artículo } 7 \\
\text { letra c) }\end{array}$ & $\begin{array}{l}\text { Reglamento de Evaluación } \\
\text { Ambiental Estratégica }\end{array}$ \\
\hline $\begin{array}{l}\text { Planes de Prevención } \\
\text { o Descontaminación } \\
\text { Atmosférica (PPDA) }\end{array}$ & Ley 19.300 & No establece & Reglamento PPDA \\
\hline Planes de manejo & Ley 19.300 & No establece & \\
\hline $\begin{array}{l}\text { Estrategia climática de } \\
\text { largo plazo }\end{array}$ & $\begin{array}{l}\text { Proyecto de } \\
\text { ley marco } \\
\text { de cambio } \\
\text { climático }\end{array}$ & $\begin{array}{l}\text { Artículo } 5, \\
\text { proyecto de } \\
\text { ley marco } \\
\text { de cambio } \\
\text { climático }\end{array}$ & $\begin{array}{l}\text { Reglamento del Ministerio del } \\
\text { Medio Ambiente }\end{array}$ \\
\hline $\begin{array}{l}\text { Contribución } \\
\text { Determinada a Nivel } \\
\text { Nacional }\end{array}$ & $\begin{array}{l}\text { Proyecto de } \\
\text { ley marco } \\
\text { de cambio } \\
\text { climático }\end{array}$ & $\begin{array}{l}\text { Artículo } 7, \\
\text { proyecto de } \\
\text { ley marco } \\
\text { de cambio } \\
\text { climático }\end{array}$ & $\begin{array}{l}\text { Reglamento del Ministerio del } \\
\text { Medio Ambiente }\end{array}$ \\
\hline $\begin{array}{l}\text { Planes Sectoriales de } \\
\text { Mitigación al Cambio } \\
\text { Climático }\end{array}$ & $\begin{array}{l}\text { Proyecto de } \\
\text { ley marco } \\
\text { de cambio } \\
\text { climático }\end{array}$ & $\begin{array}{l}\text { Artículo } 8, \\
\text { proyecto de } \\
\text { ley marco } \\
\text { de cambio } \\
\text { climático }\end{array}$ & $\begin{array}{l}\text { Reglamento del Ministerio del } \\
\text { Medio Ambiente }\end{array}$ \\
\hline $\begin{array}{l}\text { Planes Sectoriales de } \\
\text { Adaptación al Cambio } \\
\text { Climático }\end{array}$ & $\begin{array}{l}\text { Proyecto de } \\
\text { ley marco } \\
\text { de cambio } \\
\text { climático }\end{array}$ & $\begin{array}{l}\text { Artículo 9, } \\
\text { proyecto de } \\
\text { ley marco } \\
\text { de cambio } \\
\text { climático }\end{array}$ & $\begin{array}{l}\text { Reglamento del Ministerio del } \\
\text { Medio Ambiente }\end{array}$ \\
\hline $\begin{array}{l}\text { Reporte de Acción } \\
\text { Nacional de Cambio } \\
\text { Climático }\end{array}$ & $\begin{array}{l}\text { Proyecto de } \\
\text { ley marco } \\
\text { de cambio } \\
\text { climático }\end{array}$ & $\begin{array}{l}\text { No contempla } \\
\text { PAC }\end{array}$ & \\
\hline
\end{tabular}




\begin{tabular}{|c|c|c|c|}
\hline $\begin{array}{l}\text { Planes de Acción } \\
\text { Regional de Cambio } \\
\text { Climático }\end{array}$ & $\begin{array}{l}\text { Proyecto de } \\
\text { ley marco } \\
\text { de cambio } \\
\text { climático }\end{array}$ & $\begin{array}{l}\text { No contempla } \\
\text { PAC }\end{array}$ & \\
\hline $\begin{array}{l}\text { Planes Estratégicos de } \\
\text { Recursos Hídricos en } \\
\text { Cuencas }\end{array}$ & $\begin{array}{l}\text { Proyecto de } \\
\text { ley marco } \\
\text { de cambio } \\
\text { climático }\end{array}$ & $\begin{array}{l}\text { No contempla } \\
\text { PAC }\end{array}$ & \\
\hline $\begin{array}{l}\text { Normas de emisión } \\
\text { de gases de efecto } \\
\text { invernadero }\end{array}$ & $\begin{array}{l}\text { Proyecto de } \\
\text { ley marco } \\
\text { de cambio } \\
\text { climático }\end{array}$ & $\begin{array}{l}\text { Artículo } 13, \\
\text { proyecto de } \\
\text { ley marco } \\
\text { de cambio } \\
\text { climático }\end{array}$ & $\begin{array}{l}\text { Reglamento del Ministerio del } \\
\text { Medio Ambiente }\end{array}$ \\
\hline $\begin{array}{l}\text { Certificados de reducción } \\
\text { de emisiones }\end{array}$ & $\begin{array}{l}\text { Proyecto de } \\
\text { ley marco } \\
\text { de cambio } \\
\text { climático }\end{array}$ & $\begin{array}{l}\text { No contempla } \\
\text { PAC }\end{array}$ & $\begin{array}{l}\text { Reglamento del Ministerio del } \\
\text { Medio Ambiente }\end{array}$ \\
\hline
\end{tabular}

Séptimo, si uno estima que la participación ciudadana es un derecho humano, solo cabría su regulación por ley, por aplicación del artículo 19 numeral 26..$^{\circ}$ en relación con el artículo 32, numeral sexto, ambos de la Constitución.

Octavo, claramente la normativa ambiental chilena considera que la participación ciudadana es un derecho de carácter instrumental, que puede ser regulada por la potestad reglamentaria del presidente de la República. Creemos que esa es la interpretación que se ha dado en la normativa ambiental chilena, ya que, si no fuese así, todas las regulaciones en el ámbito reglamentario serían derechamente inconstitucionales. 


\section{BIBLIOGRAFÍA}

- Castellà, Josep María. Los derechos constitucionales de participación política en la Administración Pública. Barcelona: Cedec, 2001.

- Costa Cordella, Ezio. Participación ciudadana: Conceptos generales, deliberación y medio ambiente. Santiago: Der, 2020.

- Gómez González, Rosa. «Rol e importancia de las leyes de bases en el Derecho Administrativo chileno». Revista de Derecho (Valdivia) 29, n. ${ }^{\circ}$ 2 (2016): 213-228. https://doi.org/10.4067/S0718-09502016000200010

- Lara, Martín y Diego Letelier. «Mecanismos de participación ciudadana en el Sistema de Evaluación de Impacto Ambiental chileno». Revista de Gestión Pública 6, n. ${ }^{\circ} 2$ (2017): 283-314. https://doi.org/10.22370/ rgp.2017.6.2.2210

- Moreno Santander, Carlos. Participación ciudadana en la Ley 19.300, sobre Bases Generales del Medio Ambiente. Santiago: Lexis Nexis, 2004.

- Pinto, Mónica. «El principio pro homine: Criterios de hermenéutica y pautas para la regulación de los derechos humanos». En La aplicación de los tratados sobre derechos humanos por los tribunales locales, com-

pilado por Martín Abregú, 163-172. Buenos Aires: Centro de Estudios Legales y Sociales, 1997. 
REVISTA DE DERECHO APLICADO LLM UC • NÚMERO 7 • JULIO $202 \mathrm{I}$

\section{JURISPRUDENCIA CITADA}

- Corte Interamericana de Derechos Humanos. «Opinión consultiva OC-23/17 de 15 de noviembre de 2017 solicitada por la República de Colombia».

- Corte Suprema. «Oficio 138-2020 Informe Proyecto de Ley N²62020», 27 de julio de 2020. 